\title{
ERRATUM
}

\section{A composite phase conjugator based on Brillouin-enhanced four-wave mixing combining with stimulated Brillouin amplification}

\author{
C.Y. ZHU, Z.W. LU AND W.M. HE
}

Institute of Opto-electronics, Harbin Institute of Technology, Harbin, China

(Volume 27, Number 4, 2009, pages 681-687)

Because of production problem, Figure 1b and Figure 3 lost some of the detail, and we are reprinting the correct figures below.

On page 683, right hand column, line 17 the following:

$$
I_{3 p}=5 \mathrm{MW} / \mathrm{cm}^{2}
$$

should be corrected to:

$$
I_{1 p}=5 \mathrm{MW} / \mathrm{cm}^{2 \prime \prime}
$$

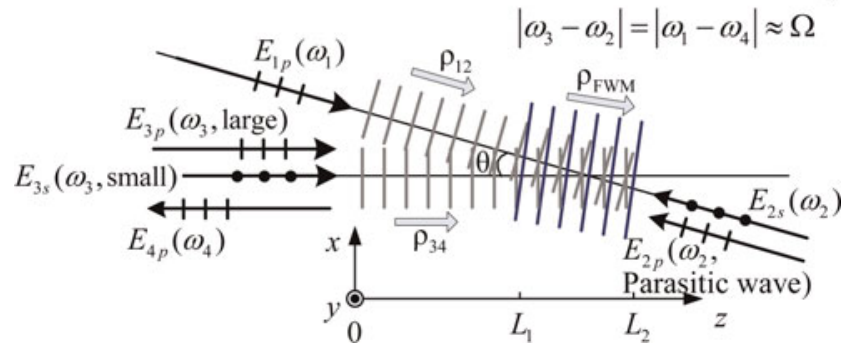

Fig. 1.

(e-mail: zw_lu@sohu.com)

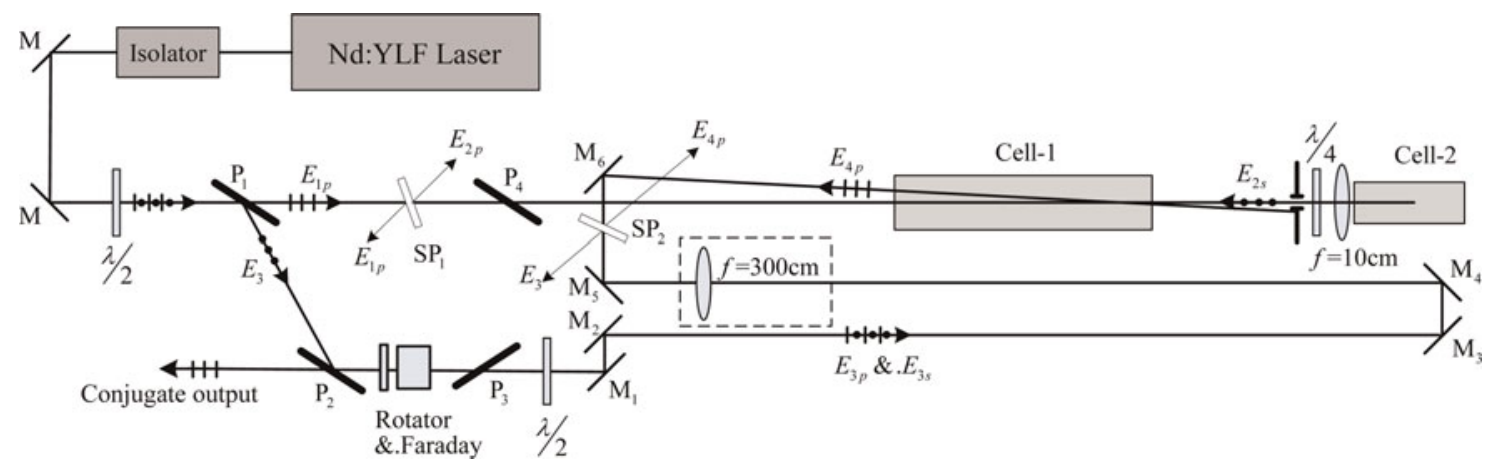

Fig. 3. 